\title{
黄土高陡边坡稳定性分析 以靖边县某黄土高陡边坡为例
}

\author{
徐江波*
}

陕西金瑞市政公路勘察设计咨询有限公司，陕西 723000

摘 要: 本文通过榆林市靖边县某黄土高陡边坡典型案例, 在详细勘察的基础上, 利用Geostudio/Slope (2012) 软件进行天然 状态、考虑荷载/考虑荷载及连续降雨或暴雨等三种工况下边坡稳定量和应力应变分析, 提出以削方减载加坡面整治为主的综合治理 措施。

关键词：黄土; 高陡边坡; 稳定性分析

\section{Stability Analysis of High and Steep Loess Slope — Taking A High and Steep Loess Slope in Jingbian County as An Example}

\author{
Jiang-Bo Xu* \\ Shaanxi Xinrui Municipal Highway Survey and Design Consulting Co., Ltd., Hanzhong 723000, Shaanxi, China
}

\begin{abstract}
Based on the detailed investigation of typical case of the high and steep loess slope in Jingbian county, Yulin city, the software Geostudio/Slope (2012) was used to analyze the slope stability and stress-strain under three working conditions: natural state, load and continuous rainfall or rainstorm. Comprehensive management measures are proposed, which mainly focus on cutting load and improving slope stability.
\end{abstract}

Keywords: Loess; high and steep slopes; stability analysis

\section{一、引言}

近年来, 在黄土地区特别是陕北, 随着建筑物的大量兴建和人们对空间的不断开发、利用, 黄土高陡边坡越来越多。由于对黄 土边坡复杂性认识不足, 加上黄土本身的特殊性, 边坡工程事故频发, 给国家经济及人民生命财产造成巨大损失。岩土工程界普遍 认为引起边坡失稳事故的主要原因是工程地质勘查存在问题、边坡支护设计存在问题、边坡施工存在问题及边坡工程在使用中存在 问题 ${ }^{[1]}$ 。工程地质勘查的目的就是为设计及施工提供工程地质依据，对边坡稳定性的判定对设计及施工均具有指导意义。

对高陡边坡段到等 ${ }^{[2-3]}$ 分别从弹塑性变形、应力-应变曲线关系方面研究黄土特性。胡晋川 ${ }^{[4]}$ 、孙超等 ${ }^{[5]}$ 从突变等研究了黄土高原 区滑坡和崩塌的发育类型、形成特征及分布特征。刘保健等 ${ }^{[6}$ 理论研究黄土边坡稳定性分析方法。榆林作为毛乌素沙漠和黄土梁峁丘 陵区的过渡地带, 该地区黄土高陡边坡稳定性研究的相关文献不多。本文选择靖边县某典型黄土边坡作为研究对象, 在详细勘察的 基础上，利用Geostudio/Slope（2012）软件对该高陡边坡的稳定性进行评价，并提出相应的工程治理措施，并对治理效果进行验算。

\section{二、工程概况}

研究区地貌单元属靖边县中部梁峁涧地区, 属堆积剥蚀地形, 地表形态以黄土梁峁为主, 梁缓涧宽, 梁涧相间。属半干旱内陆 季风气候, 四级变化明显, 年平均气温 $8.8^{\circ} \mathrm{C}$, 绝对最高温度 $36.4^{\circ} \mathrm{C}$, 绝对最低温度 $-27.3^{\circ} \mathrm{C}$ 。年平均降雨量 $384.7 \mathrm{~mm}$, 最大日降雨量 $113.2 \mathrm{~mm}$, 主要集中7、8、9三月。年平均蒸发量 $1957.9 \mathrm{~mm}$ 。年平均蒸发量 $1957.9 \mathrm{~mm}$ 。县内风多且大, 年平均风速为 $2.3 \mathrm{~m} / \mathrm{s}$, 最 大风速 $16.0 \mathrm{~m} / \mathrm{s}$ 。风向以南风居多, 西风次之。地面温度 $11.0^{\circ} \mathrm{C}$, 绝对最高温度 $68.4^{\circ} \mathrm{C}$, 绝对最低温度 $-37.1^{\circ} \mathrm{C}$ 。标准冻深 $79 \mathrm{~cm}$, 最 大冻土深度 $115 \mathrm{~cm}$ 。

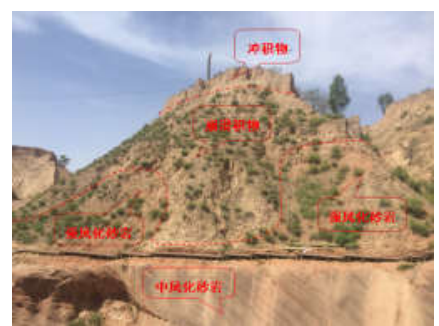

图1 高陡边坡形态及地质结构

*通讯作者: 徐江波, 1981年10月, 男, 汉族, 山东济宁人, 现任陕西輇瑞市政公路勘察设计咨有限公司副总工程师, 程师, 大学本科。研究方向: 工程地质。 
研究区地层主要为第四系晚更新统冲黄土状土 $\left(\mathrm{Q}_{3}{ }^{\mathrm{al}}\right)$ 、中生界白严系下统志丹群洛河组 $\left(\mathrm{K}_{1} \mathrm{~L}\right)$ 砂岩组成, 呈典型黄土+基岩 地质结构类型，勘探深度范围内未见地下水，如图1所示。

\section{三、稳定性分析}

（一）边坡稳定量计算分析

边坡稳定性计算选用Geostudio/Slope (2012) 软件的毕肖普法, 选取坡体1-1' 3-3'典型断面对其进行稳定计算分析。计算时分 为三种工况, 即工况 I (天然状态)、工况 II (考虑荷载) 与工况 III (考虑荷载及连续降雨或暴雨) 等。同时, 由于边坡后缘平台 已出现拉张裂缝，计算时以裂缝为潜在滑裂面边界，如表1、表2所示。

表1 边坡稳定性计算参数表

\begin{tabular}{|c|c|c|c|c|}
\hline 计算工况 & 地层岩性 & 重度 $\gamma\left(\mathrm{kN} / \mathrm{m}^{3}\right)$ & 内摩擦角 $\varphi\left({ }^{\circ}\right)$ & 粘聚力 ${ }^{\circ} \mathrm{C}(\mathrm{kPa})$ \\
\hline \multirow{2}{*}{ 天然状态 $($ 工况 I ) } & 黄土 & 17.1 & 31 & 27 \\
\cline { 2 - 5 } & 泥质砂岩 & 17.0 & 35 & 40 \\
\hline \multirow{2}{*}{ 考虑荷载 (工况 II ) } & 黄土 & 17.1 & 35 & 40 \\
\cline { 2 - 5 } & 泥质砂岩 & 17.0 & 25 & 25 \\
\hline \multirow{2}{*}{ 考虑荷载与降雨 (工况 III ) } & 黄土 & 18.5 & 32 & 35 \\
\cline { 2 - 5 } & 泥质砂岩 & 17.6 & & 45 \\
\hline
\end{tabular}

表2 边坡稳定性计算结果

\begin{tabular}{|c|c|c|}
\hline 计算工况 & 断面编号 & 稳定系数 $F_{s}$ \\
\hline \multirow{3}{*}{ 天然状态 ( 工况 I ) } & $1-1^{\prime}$ & 1.097 \\
\hline & $2-2^{\prime}$ & 1.073 \\
\hline & $3-3^{\prime}$ & 1.098 \\
\hline \multirow{3}{*}{ 考虑荷载（工况 II ） } & $1-1^{\prime}$ & 0.932 \\
\hline & $2-2^{\prime}$ & 1.017 \\
\hline & $3-3^{\prime}$ & 1.012 \\
\hline \multirow{3}{*}{ 考虑荷载与降雨（工况 III） } & $1-1^{\prime}$ & 0.809 \\
\hline & $2-2^{\prime}$ & 0.926 \\
\hline & $3-3^{\prime}$ & 0.972 \\
\hline
\end{tabular}

根据表2计算结果，结合《建筑边坡工程技术规范》 ( GB50330-2013) 表5.3.1与《滑坡防治工程勘查规范》 ( GBT328642016 ）表7针对边坡或滑坡稳定性状态划分依据可以看出，该边坡在天然状态下稳定系数1.073 1.098，均值1.089，处于基本稳定状 态; 考虑荷载后其稳定系数为 0.932 1.017, 均值 0.987 , 处于不稳定状态; 当考虑荷载与连续降雨或暴雨共同作用时其稳定系数为 0.809 0.972, 均值0.902, 处于不稳定状态。因此，综合判定该边坡处于不稳定状态。

( 1 ) 工况 I 稳定性结果图

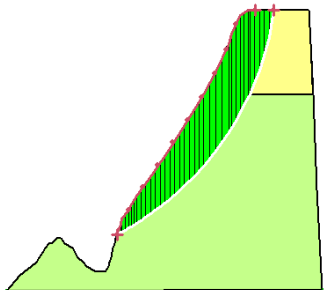

1-1'断面

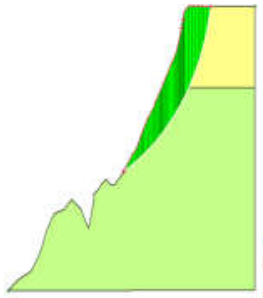

2-2'断面

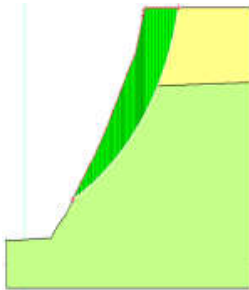

3-3'断面

（2）工况 II 稳定性结果图

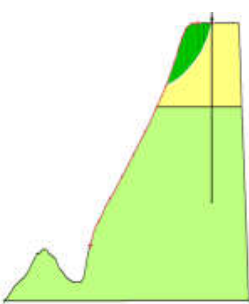

1-1'断面

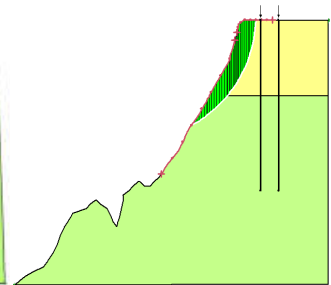

2-2'断面

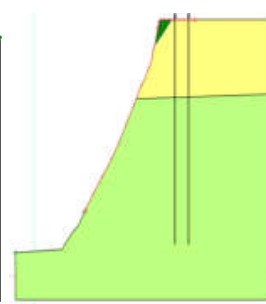

3-3'断面 
（３）工况 III稳定性结果图

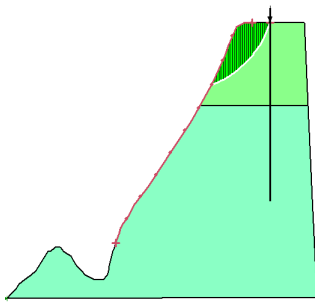

$1-1^{\prime}$ 断面

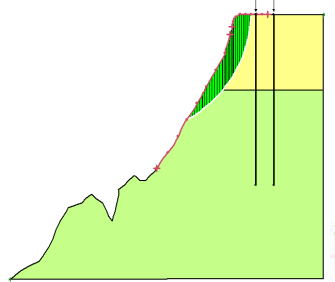

2-2'断面

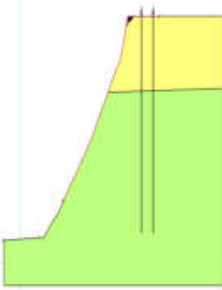

3-3'断面

(二) 边坡应力应变分析

为了分析边坡的应力应变情况，选用Geostudio/Sigma（2012）软件，根据边坡坡型及地质结构建立了 1-1' 3-3'数值分析模型， 模型左右两侧采用水平约束, 底部边界采用水平与坚直均约束条件, 同时选用6节点三角形平面应变单元进行网格剖分。假定岩土 体为弹塑性体, 破坏准则选用摩尔库伦强度准则。计算时分为三种工况, 即工况 I（天然状态）、工况 II (考虑荷载) 与工况 III (考虑荷载及连续降雨或暴雨) 等。

表3 边坡稳定性计算参数表

\begin{tabular}{|c|c|c|c|c|c|c|}
\hline 计算工况 & 地层岩性 & 重度 $\gamma\left(\mathrm{kN} / \mathrm{m}^{3}\right)$ & 摩擦角 $\varphi\left({ }^{\circ}\right)$ & 粘聚力 ${ }^{\circ} \mathrm{C}(\mathrm{kPa})$ & 弹性模量 $E(\mathrm{MPa})$ & 泊松比 $\mu$ \\
\hline \multirow{2}{*}{ 天然状态 ( 工况 I ) } & 黄土状土 & 17.1 & 31 & 27 & 3.0 & 0.49 \\
\hline & 泥质砂岩 & 17.0 & 35 & 40 & 25.0 & 0.25 \\
\hline \multirow{3}{*}{ 考虑荷载 ( 工况 II ) } & 黄土状土 & 17.1 & 31 & 27 & 3.0 & 0.49 \\
\hline & 泥质砂岩 & 17.0 & 35 & 40 & 25.0 & 0.25 \\
\hline & 桩基 & 25.0 & l & I & 30000 & 0.2 \\
\hline \multirow{3}{*}{ 考虑荷载与降雨 ( 工况 III ) } & 黄土状土 & 18.5 & 25 & 25 & 3.0 & 0.49 \\
\hline & 泥质砂岩 & 17.6 & 32 & 35 & 25.0 & 0.25 \\
\hline & 桩基 & 25.0 & 1 & 1 & 30000 & 0.2 \\
\hline
\end{tabular}

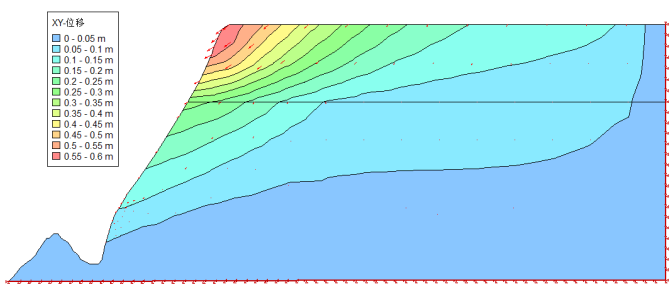

1-1'断面工况｜位移云图

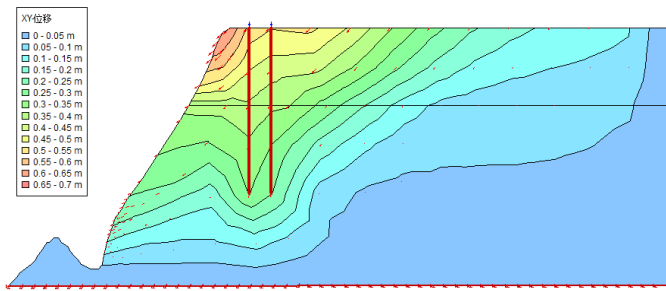

1-1'断面工况 || 位移云图

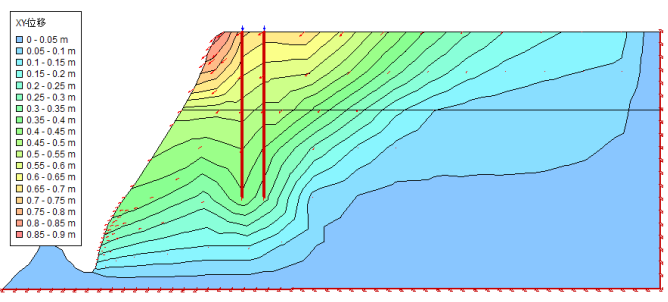

1-1'断面工况 III 位移云图

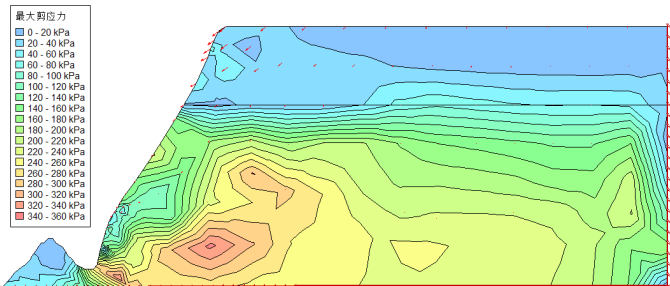

1-1'断面工况 | 剪应力云图

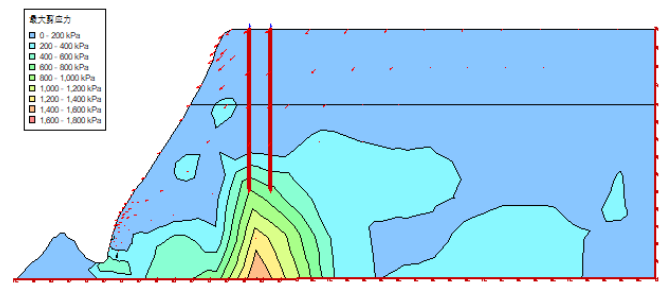

1-1'断面工况 || 剪应力云图

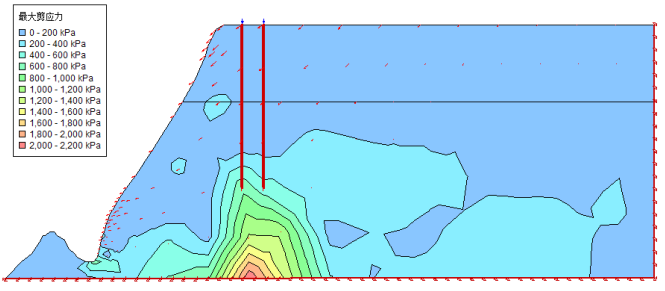

1-1'断面工况 II 位剪应力云图

不同工况下的最大位移及剪应力值统计列于表 4 。 
表4 三种工况下最大位移及剪应力统计表

\begin{tabular}{|c|c|c|c|}
\hline 工况 & 断面编号 & 最大位移 $s(\mathrm{~m})$ & 最大剪应力 $\tau_{\max }(\mathrm{kPa})$ \\
\hline \multirow{3}{*}{ 天然状态 ( 工况 I ) } & $1-1^{\prime}$ & 0.5884 & 345.71 \\
\cline { 2 - 4 } & $2-2^{\prime}$ & 1.6677 & 397.12 \\
\cline { 2 - 4 } & $3-3^{\prime}$ & 0.8549 & 1615.60 \\
\hline \multirow{3}{*}{ 考虑荷载 (工况 II ) } & $1-1^{\prime}$ & 0.6518 & 1785.30 \\
\cline { 2 - 4 } & $2-2^{\prime}$ & 2.2817 & 321.65 \\
\hline \multirow{3}{*}{ 考虑荷载与降雨 (工况 III ) } & $3-3^{\prime}$ & 0.6816 & 2169.10 \\
\cline { 2 - 4 } & $1-1^{\prime}$ & 0.8687 & 2143.30 \\
\cline { 2 - 4 } & $2-2^{\prime}$ & 2.7365 & 383.62 \\
\hline
\end{tabular}

由表4可以看出, 施工完成后, 即边坡最大剪应力由工况 I 的 $342.91 \mathrm{kPa}$ 增加到工况 III 的 $1565.34 \mathrm{kPa}$, 其剪应力增加 1222.43 $\mathrm{kPa}$, 而水平最大位移由工况 I 的 $1.03 \mathrm{~m}$ 增加到工况 $I I I$ 的 $1.47 \mathrm{~m}$, 其水平位移量增加 $0.44 \mathrm{~m}$ 。由此可以看出, 施工对边坡稳定性影响 较大, 建议加强边坡的工程防护。

\section{四、工程治理措施}

前已述及, 目前该边坡稳定性较差, 边坡后缘已出现裂缝, 加之边坡上部呈直立状, 黄土状土极易出现崩（滑）塌灾害, 因 此，建议对该边坡采取削方减载、坡面整治及修筑截排水措施等综合治理方案。

(一) 削方减载

根据前述分析可以看出，该段边坡所处地质环境较为特殊，即三面临空地形地貌、土体湿陷性及垂直节理发育的地质条件，边 坡后缘已出现裂缝, 加之边坡顶部存在危岩体。因此, 为了保证该索塔边坡的稳定性, 建议对其进行削方卸载, 削方边界最小应至 坡顶平台裂缝处，且将边坡顶部危岩体清除。

同时, 为了分析削方后边坡稳定性变化情况, 对其重新进行稳定性验算, 计算时考虑索台的两种实际工况，即工况 II（考虑荷 载）与工况 III（考虑荷载及连续降雨或暴雨）。计算参数选取见表 $1 ，$ 计算结果见表 5 。

(1) 减载后工况 II 稳定性结果图

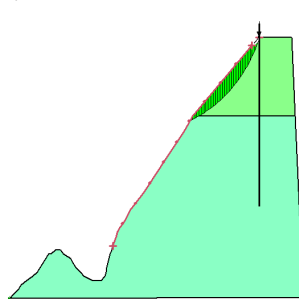

$1-1^{\prime}$ 断面

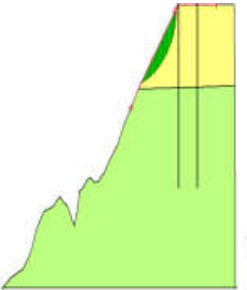

2-2'断面

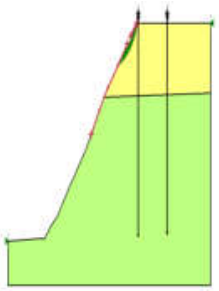

3-3'断面

(2) 减载后工况 III 稳定性结果图

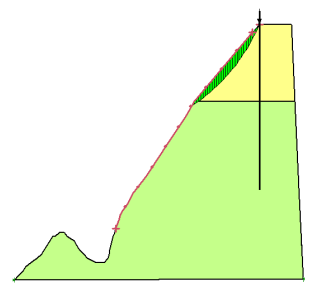

1-1'断面

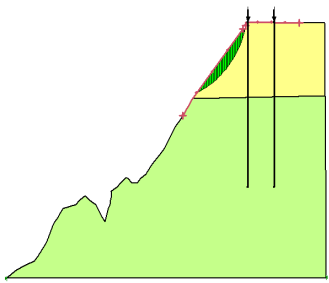

2-2'断面

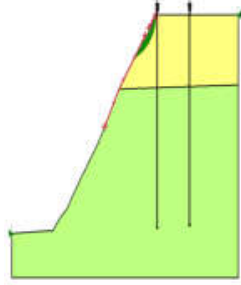

3-3'断面

表5 削方减载后边坡稳定性计算结果

\begin{tabular}{|c|c|c|}
\hline 工况 & 断面编号 & 1.16 \\
\hline \multirow{3}{*}{ 考虑荷载 ( 工况 II ) } & $1-1^{\prime}$ & 1.35 \\
\cline { 2 - 3 } & $2-2^{\prime}$ & 1.19 \\
\cline { 2 - 3 } & $3-3^{\prime}$ & 1.07 \\
\hline \multirow{3}{*}{ 考虑荷载与降雨 ( 工况 III ) } & $1-1^{\prime}$ & 1.26 \\
\cline { 2 - 3 } & $2-2^{\prime}$ & 1.05 \\
\cline { 2 - 3 } & $3-3^{\prime}$ & 1.05 \\
\hline
\end{tabular}


由表 5 计算结果, 边坡削方卸载后, 考虑荷载作用下的边坡稳定系数1.16 1.35, 均值 1.23 , 处于稳定状态; 考虑荷载及连续降 雨或暴雨共同作用下边坡稳定系数为 $1.05 \sim 1.26$ ，均值为 1.13 ，处于基本稳定状态。

(二) 边坡坡面整治及防护措施

边坡上部黄土状土呈直立状, 部分脱离母岩呈孤立状, 极易发生崩塌。通过削方处理可将裂缝与直立状的危险消除掉。但由于 场地所限, 削方后形成的边坡坡度较大 ( $\left.55^{\circ}\right)$, 稳定性验算结果表明, 边坡削方卸载后, 考虑荷载作用下的边坡处于稳定状态, 考虑荷载及连续降雨或暴雨共同作用下边坡处于基本稳定状态。为了保证削方边坡的稳定性，建议采用混凝土格构进行坡面稳定， 同时, 坡面栽植适宜当地气候条件的耐旱耐寒耐贫㾑的灌木花草进行植被防护, 以达到既能保证坡面稳定性, 又能恢复遭受工程破 坏区域生态环境 ${ }^{[7]}$ 。

边坡中下部浅层崩塌体的整治及防护。由于边坡中下部崩塌体厚度较薄且呈现出上薄下厚, 且崩塌体土质不均匀, 结构疏松, 在早期降雨入渗及冲刷作用下，坡面发育了较多的冲蚀沟、落水洞、塌陷及暗穴等。同时，披覆于砂岩之上崩滑坡积物，阻止了内 部泥质砂岩风化剥蚀, 完全清除不既不经济且不安全, 因此, 建议采用人工自上而下对坡面的落水洞、塌陷及暗穴进行夯实处理, 并采取混凝土格构固定坡面, 在此基础上, 栽植适宜当地气候条件的耐旱耐寒耐贫㾑的灌木花草, 减少坡面泥流及水土流失防止坡 面冲刷。同时，应加强坡面的排水措施。

(三) 截排水措施

1. 对施工区地表进行硬化处理，其次设置截排水渠，防止水流人渗。

2. 将水流引人北侧或东侧的天然冲沟内排出台面，严禁水流进入边坡体，造成下部坡面冲刷。

\section{五、结论}

通过分析可以看出, 影响黄土高陡边坡稳定性的因素主要有内在因素 (黄土湿陷性、边坡坡度、地下水) 和外部因素 (地震、 工程荷载、人为因素 ) 等。其中内在因素起控制性作用，外部因素起诱发作用 ${ }^{[8]}$ 。

削方减载可以极大地降低边坡在暴雨及外部荷载情况下失稳的可能性, 在保证安全的前提下, 应根据工程的具体情况采取经济 合理的治理措施。

\section{参考文献:}

[1]顾姝伟.山西某黄土边坡的稳定性分析[D].河北工程大学, 2016.

[2]段钊,李文可,王启耀.泾河下游台塬区黄土滑坡类型与时空分布规律[J].西安科技大学学报, 2015,35(3):369-375.

[3]段钊.黄土滑坡触发机理研究一以泾河下游南岸黄土塬区滑坡为例[D]长安大学, 2013:1-20.

[4]胡晋川.基于突变理论的黄土边坡稳定性分析方法研究[D].长安大学, 2011:1-64.

[5]孙超,吕一彦,吴继敏.大型堆积体边坡极限平衡稳定性分析 [J].水利与建筑工程学报, 2014,12(1):147-150.

[6]刘保健,谢定义,谢永利,赵丽娅.土的自适应应力认识与研究[J].岩土工程学报, 2015,37(7):1288-1293.

[7]史兴奇.简析边坡的坡面防护[J].黑龙江交通科技, 2016,8:66-66.

[8]刘洋,刘润,程辉,门玉明.黄土高陡边坡稳定性研究[J].水利与建筑工程学报, 2017,15(3):92-122. 